\title{
Comparing prioritization strategies for delivering indoor residual spray (IRS) implementation, using a network approach
}

Sadie J. Ryan ${ }^{1,2^{*}} \mathbb{D}$, Anne C. Martin ${ }^{3}$, Bhavneet Walia ${ }^{4}$, Anna Winters ${ }^{3,5}$ and David A. Larsen ${ }^{4}$

\begin{abstract}
Background: Indoor residual spraying (IRS) is an effective method to control malaria-transmitting Anopheles mosquitoes and often complements insecticide-treated mosquito nets, the predominant malaria vector control intervention. With insufficient funds to cover every household, malaria control programs must balance the malaria risk to a particular human community against the financial cost of spraying that community. This study creates a framework for modelling the distance to households for targeting IRS implementation, and applies it to potential risk prioritization strategies in four provinces (Luapula, Muchinga, Eastern, and Northern) in Zambia.

Methods: Optimal network models were used to assess the travel distance of routes between operations bases and human communities identified through remote sensing. Network travel distances were compared to Euclidean distances, to demonstrate the importance of accounting for road routes. The distance to reaching communities for different risk prioritization strategies were then compared assuming sufficient funds to spray $50 \%$ of households, using four underlying malarial risk maps: (a) predicted Plasmodium falciparum parasite rate in 2-10 years olds (PfPR), or (b) predicted probability of the presence of each of three main malaria transmitting anopheline vectors (Anopheles arabiensis, Anopheles funestus, Anopheles gambiae).
\end{abstract}

Results: The estimated one-way network route distance to reach communities to deliver IRS ranged from 0.05 to $115.69 \mathrm{~km}$. Euclidean distance over and under-estimated these routes by - 101.21 to $41.79 \mathrm{~km}$ per trip, as compared to the network route method. There was little overlap between risk map prioritization strategies, both at a district-bydistrict scale, and across all four provinces. At both scales, agreement for inclusion or exclusion from IRS across all four prioritization strategies occurred in less than $10 \%$ of houses. The distances to reaching prioritized communities were either lower, or not statistically different from non-prioritized communities, at both scales of strategy.

Conclusion: Variation in distance to targeted communities differed depending on risk prioritization strategy used, and higher risk prioritization did not necessarily translate into greater distances in reaching a human community. These findings from Zambia suggest that areas with higher malaria burden may not necessarily be more remote than areas with lower malaria burden.

Keywords: Residual spraying, Network modeling, Optimal routes, Risk mapping, Zambia, Malaria

\footnotetext{
*Correspondence: sjryan@ufl.edu

${ }^{1}$ Quantitative Disease Ecology and Conservation (QDEC) Lab,

Department of Geography, University of Florida, Gainesville, FL 32611, USA

Full list of author information is available at the end of the article
}

\begin{abstract}
Background
Indoor residual spray (IRS) is an effective method to control the Anopheles mosquitoes that transmit malaria [1]. The intervention has helped drive success in decreasing malaria transmission across sub-Saharan Africa $[2,3]$. IRS is often seen as complementary to the use of
\end{abstract}

(c) The Author(s) 2020. This article is licensed under a Creative Commons Attribution 4.0 International License, which permits use, sharing, adaptation, distribution and reproduction in any medium or format, as long as you give appropriate credit to the original author(s) and the source, provide a link to the Creative Commons licence, and indicate if changes were made. The images or other third party material in this article are included in the article's Creative Commons licence, unless indicated otherwise in a credit line to the material. If material is not included in the article's Creative Commons licence and your intended use is not permitted by statutory regulation or exceeds the permitted use, you will need to obtain permission directly from the copyright holder. To view a copy of this licence, visit http://creativeco mmons.org/licenses/by/4.0/. The Creative Commons Public Domain Dedication waiver (http://creativecommons.org/publicdomain/ zero/1.0/) applies to the data made available in this article, unless otherwise stated in a credit line to the data. 
insecticide-treated mosquito nets (ITN), which is the predominant vector control intervention to prevent malaria transmission $[3,4]$.

In contrast to ITNs, which in 2011 cost an estimated $\$ 2.20$ per year of protection delivered, IRS was much more expensive [5]. Using the chemicals DDT, pyrethroids, deltamethrin, and lambdacyhalothrin, the cost of IRS was $\$ 6.70$ per year of protection per household, with the cost of insecticide ranging from 29 to $81 \%$ of the total cost and minimal economies of scale [5]. With second generation ITNs and the drive for lower insecticides for IRS these prices have changed somewhat over the past 10 years. Pyrethroids have decreased in cost substantially over the past 25 years [6], but widespread insecticide resistance threatens the long-term viability of using pyrethroids for malaria control [7-9]. Currently no alternative insecticides for ITNs are available for use at scale, although novel chemicals and dual-chemical ITNs are in various stages of development. Alternative insecticides for IRS are available but come at a greater cost than those of DDT, pyrethroids, deltamethrin, and lambdacyhalothrin. Indeed, IRS programmes funded by the organizations such as the US President's Malaria Initiative (PMI) have seen reductions in coverage due to the increasing cost of insecticide [10].

Often countries are faced with the challenge of insufficient funds to cover every household in malaria endemic areas, and as such are forced to determine which houses receive the intervention. Zambia's National Malaria Elimination Centre (NMEC) has encountered this challenge; in at least some areas health facility malaria incidence is used to prioritize areas to receive IRS [11]. Recent work suggests that using vector probability maps has greater impact on malaria transmission than human case data [12]. Other approaches have also been used to prioritize which areas receive IRS, but whichever methodology is used, malaria programmes must balance the malaria risk of a particular human community with the financial cost of spraying a particular human community.

The use of network modelling for optimizing the distribution of goods along road networks is commonly used for market analyses [13, 14], and has been applied in the health arena to least-cost routing for hospital access [15-17] and delivery of vaccines [18, 19]. Several authors have noted that a primary limitation to application of network modelling in the developing world is the availability of accurately mapped road networks $[20,21]$. This article creates a framework for modelling the cost of IRS implementation and applies that framework to potential intervention prioritization strategies in Zambia.

\section{Methods}

\section{Study area}

Zambia lies in southern Africa and has a range of malaria transmission intensity, from pre-elimination status in Southern and Lusaka provinces, to intense malaria transmission in Luapula Province. The modern history of indoor residual spray (IRS) in Zambia began in 2003 when the Government of the Republic of Zambia (GRZ) began spraying to complement the private sector's IRS campaigns. Zambia's approach is to support as many districts as possible with IRS, and resources often do not allow for complete coverage of districts. This study focuses on four provinces in the eastern part of the country: Luapula, Northern, Muchinga, and Eastern provinces (Fig. 1). Malaria indicator surveys estimate Plasmodium falciparum parasite prevalence rate to be $>25 \%$ and household ownership of at least one ITN $>50 \%$ in these areas at the time of the study [22].
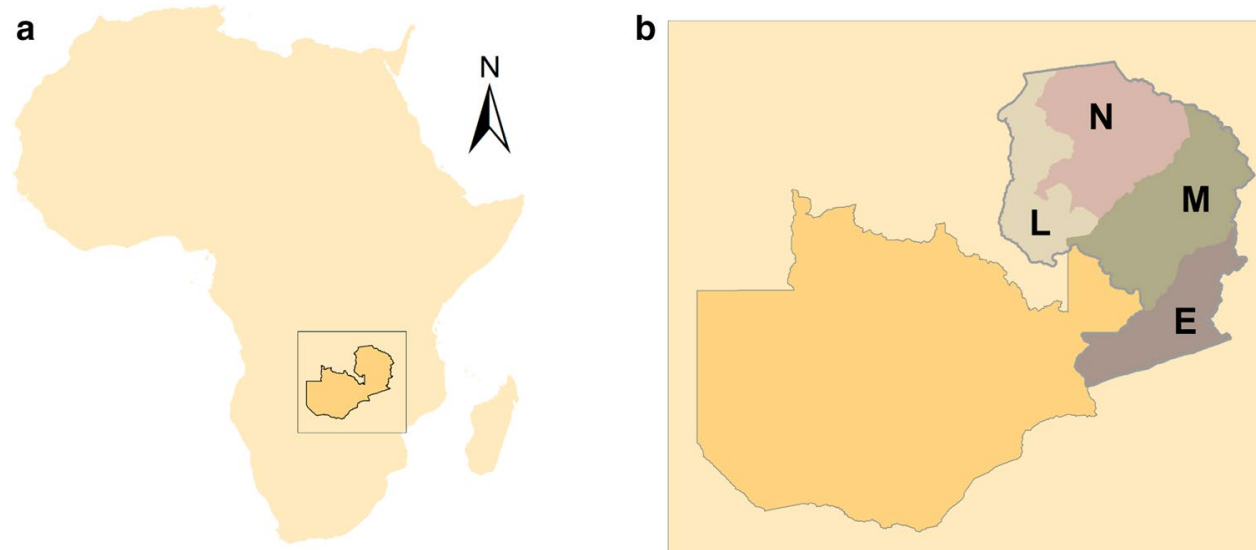

Fig. 1 The location of a Zambia in Africa, and $\mathbf{b}$ the four provinces in this study L: Luapula, N: Northern, M: Muchinga, E: Eastern 


\section{Community data}

Technicians in Lusaka, Zambia digitized structures in Eastern, Luapula, Muchinga, and Northern province visible in publicly available satellite imagery as part of the planning process of IRS campaigns in 2015 and 2016, as has been described elsewhere [23]. Digitized structures were spatially aggregated into communities based upon distance between structures $(<50 \mathrm{~m})$, and communities with fewer than 25 houses were deemed too small for IRS [11], and not included in the modelling presented here. In this study, IRS operation bases were assumed to be located at city/village centres, taken as point locations from Google Map Maker (see next section for details), totaling 236 city centre locations across the four provinces in this analysis.

\section{Road network data}

Road network data were made available to this analysis via Google Map Maker. While Google Map Maker was an openly collaborative resource during the course of this study, it was retired in March, 2017 [24, 25], and approved contributions merged with Google Maps. Google Map Maker data were chosen for this study due to more complete road network mapping than OpenStreetMap (OSM) [26], or any other digital road map resource available at the time. For the four provinces, the mapmaker (MM) road file used in this study contained a total of 13,762,691.86 $\mathrm{m}$ of roads, in 21,082 polyline segments (average segment length $653 \mathrm{~m}$ ). While MM road attributes describe 'primary' and 'local' roads separately, the absence of descriptors beyond identification meant that all roads in the network were treated equally.

\section{Network analysis}

For each province, the road network was converted to a network database in ArcGIS 10.1's Network Analysis toolbox, and impedance was set in metres. The Closest Facility analysis in ArcGIS is based on Dijkstra's algorithm [27] to find the shortest path between two specified nodes on a network, thus providing optimal routing. This algorithm calculates the distance between all nodes on a network, along all possible routes, and then for each node pair, reports the minimum of those distances. In this analysis, the shortest route between each community centroid and its nearest city centre was returned.

The centroid for each digitized community served as a destination node on the network. As many of these were not located directly on the road network, a tolerance of inclusion in the network of $5000 \mathrm{~m}$ was set, both for the city centre locations and for the community centroid locations. Since the communities were not all within
$5000 \mathrm{~m}$ of the available road network, the network analysis was conducted on a subset of actual communities and city centres, as described in Additional file 1: Table S1.

In addition to the network modelled route distance, because a tolerance of 5,000 $\mathrm{m}$ was set, the Euclidean distance from each community centroid to the nearest point on the nearest road in the network was added, and the distance along the optimal route plus distance to the nearest road was calculated, to estimate the total distance to the community centroid.

To examine the impact of modelling distribution routes as optimal network routes, rather than simple Euclidean distance routes between communities and their nearest city centres, the simple Euclidean distances were calculated, and compared to the network distances.

\section{Establishing spatial malarial risk prioritization strategies}

The distance framework was applied to two separate prioritization strategies based on underlying risk maps, namely: Plasmodium falciparum prevalence rate among kids aged $2-10$ years old $\left(P f \mathrm{PR}_{2-10}\right)$ from the Malaria Atlas Project (MAP), estimated for 2010 [28]; and MAP vector suitability for Anopheles gambiae, Anopheles funestus, and Anopheles arabiensis [29]. MAP estimates of both $P f \mathrm{PR}_{2-10}$ and vector suitability estimates are available from the malariaAtlas package in $R$ [30]. Mean estimates were extracted from raster files to community polygons, and aggregated to average values, using the Raster package [31, 32] in $\mathrm{R}$ version 3.3.2 [33].

\section{Analysis}

Two separate modelling strategies were employed, the "within district prioritization" and the "across district prioritization". The $50 \%$ prioritization approach was based on an assumption of budget limitations, not a coverage target for a programme. For the first strategy, half of all households within each district of the four provinces were targeted for IRS, with prioritization of communities based on one of the underlying risk maps. Second, half of all households across the four provinces were targeted for IRS with the same risk map prioritization. Since IRS is administered by community, but this study aimed to cover $50 \%$ of all households, prioritization was conducted by ranking communities in order of risk (high to low), and summing household numbers (counts within communities) from the top-ranked down, until 50\% was exhausted. $t$-tests were used to determine differences by prioritization strategy and Kappa test scores were used to estimate the agreement between prioritization strategies. To generate a measure of overall agreement between the different prioritization strategies the arithmetic mean between pair statistics was taken [34]. Stata version 13.1 was used for these analyses. 


\section{Results}

Mapping prioritized targets to a road network

The road network data used in this study represents only around a third of visible roads and tracks on the ground (Ryan, unpublished) and, therefore, should be considered a primary road network, rather than a full road network. Among the 18,448 communities created in the enumeration and digitization process, 11,146 (60.4\%) were captured to the incomplete road network. Of these communities, 3198 (28.7\%) had at least 25 houses, which would put them in consideration for IRS, and were included in further analysis. There was minimal difference in risk estimates between communities included and excluded from this study, based on PfPR, An. arabiensis, and An. funestus, and included communities had somewhat higher estimates of risk based on An. gambiae (Table 1).

\section{Road network versus Euclidean routing}

The differences between Euclidean ("straight-line") and optimal road network route distances for each province are shown as histograms in Fig. $2 \mathrm{a}-\mathrm{d}$. These show that both over and underestimates arise under a simple Euclidean distance modelled view, generating an overall range of a maximum of $41.79 \mathrm{~km}$ (overestimate) and a minimum of -101.21 (underestimate) of the distance of a one-way route to deliver spray to a community.

\section{Within district prioritization}

In the first strategy examined, district-by-district community ranked prioritization, allocated IRS to the top $50 \%$ risk households based upon use of the MAP risk approaches. As seen in Table 2, few communities were excluded from any prioritization strategy (6.9\%) and few were included within all prioritization strategies (7.4\%), indicating low levels of agreement among MAP risk strategies. In pairwise strategy comparisons, agreement was statistically better than chance between PfPR and $A n$. funestus risk, but no agreement between other prioritization strategies was observed (Additional file 1: Table S2). The overall Kappa statistic of agreement between the different prioritization strategies was -0.039 .

The distance to communities from a city centre to deliver IRS ranged from 0 to $115 \mathrm{~km}$, with $75 \%$ of communities located within $25 \mathrm{~km}$ of a city centre. Differences in distances to reach communities were higher in prioritized communities compared to non-prioritized communities for PfPR and An. funestus risk, and distances were lower in prioritized communities when based on An. gambiae risk (Table 3).

\section{Across-province prioritization}

When considering deploying IRS across the entire fourprovince study area, using the same MAP risk prioritization approach, large variations are seen in the number of communities included by strategy, within province (Table 4), leading to high district-level variation in the allocation of IRS by strategy (Fig. 3).

Similarly to the district-by-district approach, there was large disagreement in communities covered between the different risk prioritization strategies. As seen in Additional file 1: Table S3, very few communities were excluded from any prioritization strategy (3.1\%) and even fewer were included in all the prioritization strategies $(2.6 \%)$. Comparing pairwise strategy sets, agreement was statistically better than chance between PfPR and An. funestus, PfPR and An. gambiae, and An. arabiensis and $A n$. funestus. The overall Kappa statistic of agreement between the different prioritization strategies was -0.103 (Additional file 1: Table S4).

The optimal route distance to communities ranged from $53 \mathrm{~m}$ to $116 \mathrm{~km}$, with $75 \%$ of communities $25 \mathrm{~km}$ or less from a city centre. Distance to communities were no different between prioritized and non-prioritized communities for An. gambiae and PfPR prioritization, while prioritized communities were statistically nearer to city

Table 1 Differences in risk estimates (PfPR, An. arabiensis, An. funestus, An. gambiae) between communities captured to road networks (included) and those not captured to road networks (excluded)

\begin{tabular}{|c|c|c|c|}
\hline & $\begin{array}{l}\text { Mean value in non-captured } \\
\text { communities }\end{array}$ & $\begin{array}{l}\text { Mean value in captured } \\
\text { communities }\end{array}$ & $\begin{array}{l}\text { Difference between non- } \\
\text { captured and captured } \\
\text { communities }\end{array}$ \\
\hline PfPR & 0.275 & 0.267 & -0.098 \\
\hline An. arabiensis & 0.524 & 0.498 & -0.125 \\
\hline An. funestus & 0.657 & 0.639 & -0.082 \\
\hline An. gambiae & 0.345 & 0.433 & 0.405 \\
\hline Number of houses ${ }^{\mathrm{a}}$ & 103 & 125 & 0.090 \\
\hline
\end{tabular}

\footnotetext{
a log-transformed for effect estimate
} 

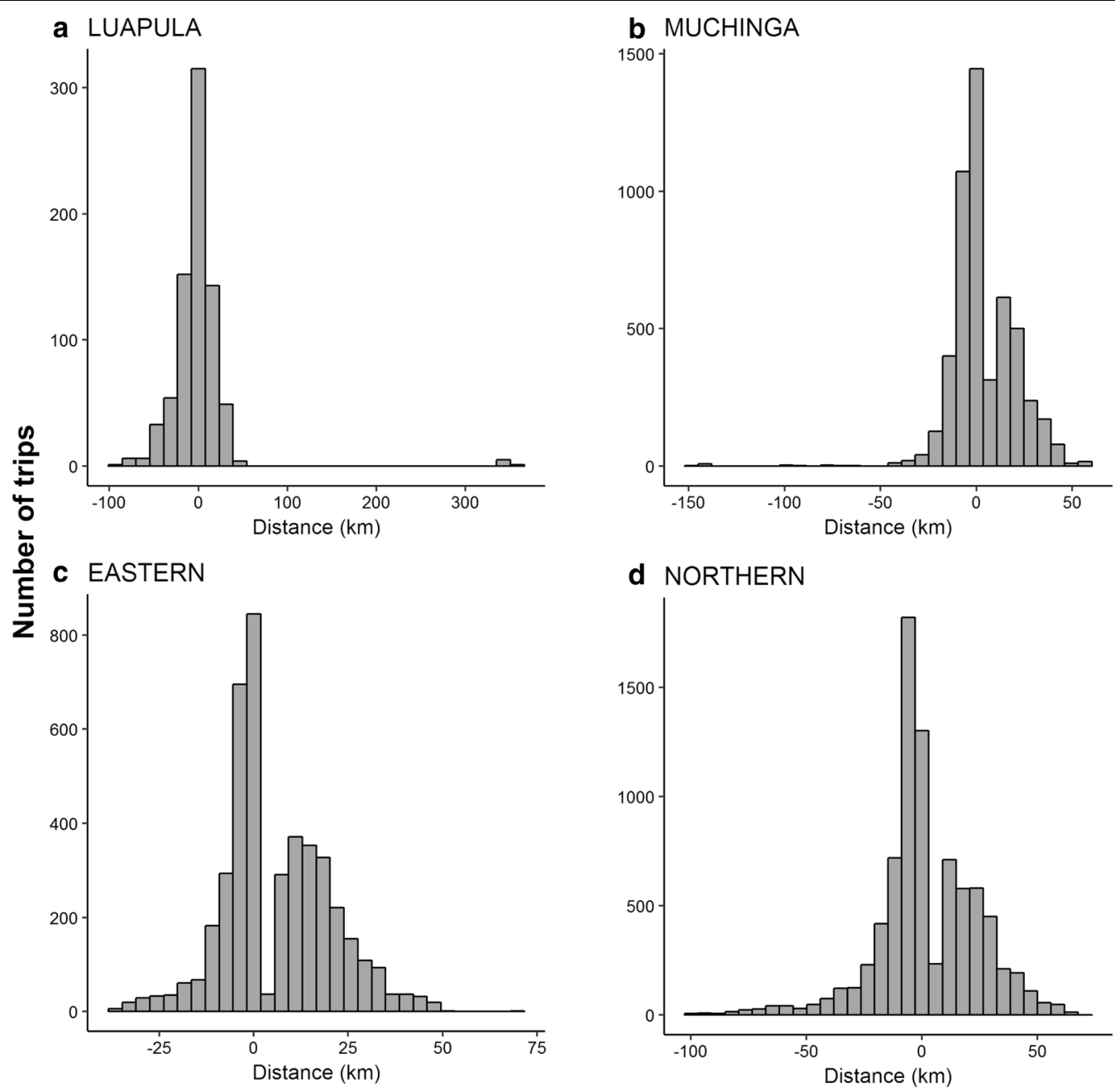

Fig. 2 The range of differences in distance, for the four provinces (a-d) between Euclidean distance and optimal network route distance from city centres to nearest target community

Table 2 Number of communities to receive IRS, under the four risk prioritization strategies (PfPR, An. arabiensis, An. funestus, An. gambiae) when spraying half of all households within each district

\begin{tabular}{lcl}
\hline & $\begin{array}{l}\text { Number } \\
\text { of communities }\end{array}$ & $\begin{array}{l}\text { Percent } \\
\text { of communities } \\
\text { (\%) }\end{array}$ \\
\hline Prioritized by zero strategies & 216 & 6.8 \\
Prioritized by one strategy & 1150 & 36.0 \\
Prioritized by two strategies & 2031 & 63.5 \\
Prioritized by three strategies & 1139 & 35.6 \\
Prioritized by four strategies & 232 & 7.3
\end{tabular}

Table 3 Mean distance to communities from city centre for prioritized (A) and non-prioritized (B) communities by different strategies, within each district (t-tests on logtransformed values)

\begin{tabular}{lllcc}
\hline Strategy & $\mathbf{A}(\mathbf{k m})$ & $\mathbf{B}(\mathbf{k m})$ & $\boldsymbol{t}$-test & $\boldsymbol{P}$-value \\
\hline PfPR & 20.1 & 17.4 & -2.71 & 0.0068 \\
An. arabiensis & 19.1 & 18.9 & -0.45 & 0.6499 \\
An. funestus & 19.2 & 18.8 & 1.72 & 0.0853 \\
An. gambiae & 16.4 & 21.5 & 5.77 & $<0.001$ \\
\hline
\end{tabular}

$\mathrm{N}=3198$ communities 
Table 4 Number of communities (and percent) included for IRS by prioritization strategy (A PfPR, B An. arabiensis, C An. funestus, D An. gambiae) when spraying half of all households across all four provinces

\begin{tabular}{lllll}
\hline $\begin{array}{l}\text { Province/ } \\
\text { Strategy }\end{array}$ & A (\%) & B (\%) & C (\%) & D (\%) \\
\hline Eastern & $391(38.3 \%)$ & $741(72.5 \%)$ & $895(87.6 \%)$ & $156(15.3 \%)$ \\
Luapula & $543(77.5 \%)$ & $196(30.0 \%)$ & $276(39.4 \%)$ & $512(73.0 \%)$ \\
Muchinga & $181(33.0 \%)$ & $310(56.6 \%)$ & $257(46.9 \%)$ & $273(49.8 \%)$ \\
Northern & $560(59.1 \%)$ & $164(17.3 \%)$ & $266(28.1 \%)$ & $593(62.6 \%)$ \\
\hline
\end{tabular}

centres based on An. arabiensis and An. funestus risk (Table 5).

\section{Discussion}

In this paper, models of allocating IRS were examined, using a combination of optimal network distributions based on road network routing, and spatial prioritization using risk maps estimating under 5 PfPR, and suitability for the three major Anopheline vectors implicated in malaria transmission in Zambia. Differences were observed in the cost to prioritize communities with higher estimates of PfPR and Anopheles species' vector capacity, whether strategizing IRS application district-by-district, or across the four provinces in the study. In many cases, reaching communities prioritized by risk strategies did not differ significantly in cost from reaching non-prioritized communities, and were in some cases cheaper. Prioritizing communities for intervention at the provincial level rather than equally allocating coverage across districts led to variation in the proportion of houses receiving IRS at the district level, as shown in Fig. 3. The findings of this study suggest areas with higher malaria burdens may not necessarily be more remote than with lower malaria burdens.

Additionally, a complete lack of agreement in IRS allocation between PfPR and vector prioritization strategies presents a challenge to malaria programmes, requiring programmes to pick which measure of risk is most appropriate given their context. Risk maps are not often used when planning malaria interventions [35], and there is little literature to suggest which prioritization strategy has the most impact on reducing malaria. Further, these analyses utilized global risk maps of malarial risk indicators rather than local risk maps. The use of global risk maps can be considered both a strength and a limitation, with data availability being one of the primary strengths. Two of the most recent malaria risk maps in Zambia were subnational, and even sub-provincial, and so would not be useful for national IRS campaigns [36, 37]. These risk maps need to be validated on a larger scale before they can be useful for malaria control programs. It remains to be seen whether localized, more specific risk maps have better agreement in prioritizing communities to receive limited IRS resources.

It has been noted by several authors that availability of accurately mapped road networks greatly limits the application of optimizing network routing models in the developing world $[20,21]$. This study demonstrated the differences in estimating route distances between using simple Euclidian distance mapping, and network routing, suggesting this is an important gap to fill for effective planning for distribution programs of many kinds. In this comparison between these two distance estimation methods, it was shown that while the overestimates given by Euclidian distance range a substantial amount, in this particular case, overestimation errs in a conservative direction for operational planning. However, the underestimates, if part of multiple round trips, could rapidly amount to large unanticipated costs for spray operations.

In this study, the best available data were used, but results must be interpreted with the data limitations in mind. Forty percent of the communities enumerated were not captured by the network analysis because they were not within $5000 \mathrm{~m}$ of the road network and were, therefore, removed from further analyses. It is likely that the road network data is incomplete, rather than that these communities are indeed more remote than their counterparts nearer to the available road data. Indeed, there was no difference in malaria risk between captured and non-captured communities by any of the four measures used herein. Investment into geospatial data such as road networks would improve predictive modelling and precision public health delivery [38] of interventions such as IRS.

Further, while this study developed a robust model, there is always notable variability in IRS operations; for example, team size and number and location of operational bases may differ across a country context, and even within a province or district. It may be that the degree of this variability differs in harder to reach areas. While this model does not fully capture that variability, it offers a basis of comparison across the prioritization strategies and creates a framework for adding such complexity in the future. A caveat to note is that these are findings from one country, Zambia, and that while the methods may prove practical to assess IRS distribution in other countries, the results may differ due to differing population density and distribution, as well as transmission patterns. 

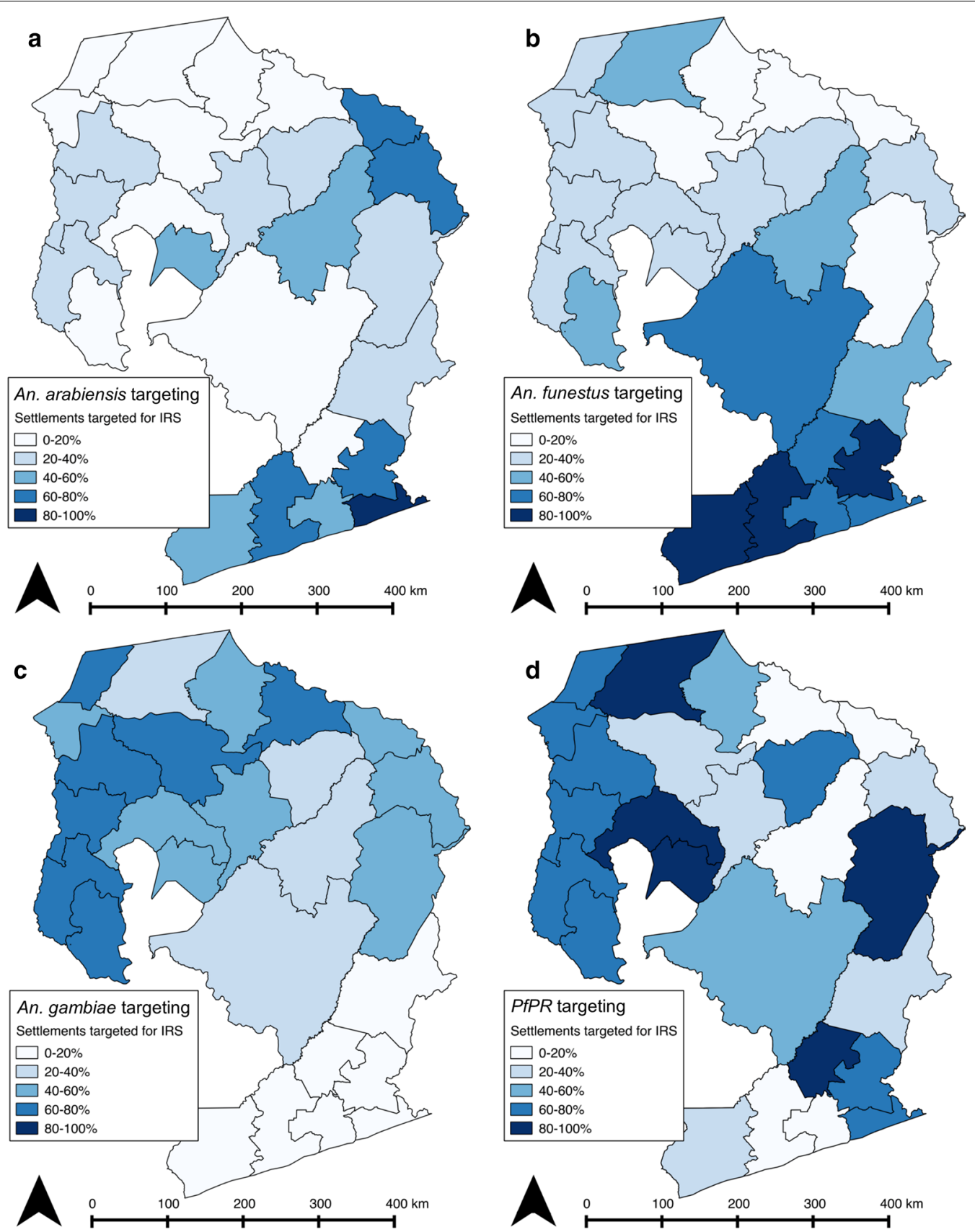

Fig. 3 Percentage of communities receiving IRS in each district by prioritization strategy (a PfPR, b An. arabiensis, c An. funestus, d An. gambiae) when spraying half of all households across all four provinces 
Table 5 Mean distance to spraying communities from city headquarters for targeted (A) and untargeted (B) communities by different strategies, across all four provinces ( $t$-test on log-transformed values)

\begin{tabular}{llllc}
\hline Strategy & $\mathbf{A}(\mathbf{k m})$ & $\mathbf{B}(\mathbf{k m})$ & $\boldsymbol{t}$-test & $\boldsymbol{P}$-value \\
\hline PAPR & 19.7 & 18.1 & 1.51 & 0.1299 \\
An. arabiensis & 16.6 & 21.1 & 3.62 & $<0.001$ \\
An. funestus & 17.3 & 21.2 & 3.44 & $<0.001$ \\
An. gambiae & 19.3 & 18.7 & 0.56 & 0.5722 \\
\hline
\end{tabular}

$\mathrm{N}=3198$ communities

\section{Conclusions}

Areas with greater malaria burden or risk of malaria transmission are not necessarily more costly to reach for intervention delivery. A lack of agreement between different risk maps may be challenging for malaria control programmes deciding how to prioritize where to spend resources.

\section{Supplementary information}

Supplementary information accompanies this paper at https://doi. org/10.1186/s12936-020-03398-z.

Additional file 1: Table S1. Number of city centre points and communities, and number included in network analyses, for the four study provinces in Zambia. Table S2. Kappa statistics for prioritizing communities $(\mathrm{N}=3218)$ between pairs of prioritization strategies, within each district. Table S3. Number of communities to receive IRS, as prioritized under the four strategies (PfPR, An. arabiensis, An. funestus, An. gambiae) when spraying half of all households across all four provinces. Table S4. Kappa statistic for prioritizing communities $(\mathrm{N}=3218)$ between pairs of prioritization strategies, when spraying half of all houses across all four provinces.

\section{Abbreviations}

IRS: Indoor residual spraying; ITN: Insecticide-treated mosquito net.

\section{Acknowledgements}

Not applicable.

\section{Authors' contributions}

SJR and DL conceived of the analytical framework; SJR, DAL, and BW conducted analyses; SJR, DAL, BW, ACM, AW wrote and edited the manuscript. All authors read and approved the final manuscript.

\section{Funding}

This work was funded by the President's Malaria Initiative through the Africa Indoor Residual Spray program.

\section{Availability of data and materials}

The satellite enumerations used in these analyses are proprietary data owned by the Zambian Ministry of Health, and request to access these enumerations can be made to the Zambian Ministry of Health. All other data used in these analyses are publicly available.

\section{Ethics approval and consent to participate} Not applicable.

\section{Consent for publication}

Both the United States President's Malaria Initiative and the Zambian National Health Research Authority reviewed the article before approving submission to a scientific journal.

\section{Competing interests}

The authors declare they have no competing interests.

\section{Author details}

${ }^{1}$ Quantitative Disease Ecology and Conservation (QDEC) Lab, Department of Geography, University of Florida, Gainesville, FL 32611, USA. ${ }^{2}$ Emerging Pathogens Institute, University of Florida, Gainesville, FL 32610, USA. ${ }^{3}$ Akros, Lusaka, Zambia. ${ }^{4}$ Department of Public Health, Syracuse University, Syracuse, NY 13210, USA. ${ }^{5}$ University of Montana School of Public and Community Health Science, Missoula, MT, USA.

Received: 27 April 2020 Accepted: 30 August 2020

Published online: 04 September 2020

\section{References}

1. Pluess B, Tanser FC, Lengeler C, Sharp BL. Indoor residual spraying for preventing malaria. Cochrane Database Syst Rev. 2010;4:CD006657.

2. O'Meara WP, Mangeni JN, Steketee R, Greenwood B. Changes in the burden of malaria in sub-Saharan Africa. Lancet Infect Dis. 2010;10:545-55.

3. Bhatt S, Weiss DJ, Cameron E, Bisanzio D, Mappin B, Dalrymple U, et al. The effect of malaria control on Plasmodium falciparum in Africa between 2000 and 2015. Nature. 2015;526:07-11.

4. Kilian A, Koenker H, Paintain L. Estimating population access to insecticide-treated nets from administrative data: correction factor is needed. Malar J. 2013;12:259.

5. White M, Conteh L, Cibulskis R, Ghani A. Costs and cost-effectiveness of malaria control interventions - a systematic review. Malar J. 2011;10:337.

6. Walker K. Cost-comparison of DDT and alternative insecticides for malaria control. Med Vet Entomol. 2000;14:345-54.

7. Mnzava AP, Knox TB, Temu EA, Trett A, Fornadel C, Hemingway J, et al. Implementation of the global plan for insecticide resistance management in malaria vectors: progress, challenges and the way forward. Malar J. 2015;14:173.

8. Hemingway J, Ranson H, Magill A, Kolaczinski J, Fornadel C, Gimnig J, et al. Averting a malaria disaster: will insecticide resistance derail malaria control? Lancet. 2016;387:1785-8.

9. Ranson H, Lissenden N. Insecticide resistance in African Anopheles mosquitoes: a worsening situation that needs urgent action to maintain malaria control. Trends Parasitol. 2016;32:187-96.

10. Oxborough RM. Trends in US President's Malaria Initiative-funded indoor residual spray coverage and insecticide choice in sub-Saharan Africa (2008-2015): urgent need for affordable, long-lasting insecticides. Malar J. 2016;15:146.

11. Pinchoff J, Larsen DA, Renn S, Pollard D, Fornadel C, Maire M, et al. Targeting indoor residual spraying for malaria using epidemiological data: a case study of the Zambia experience. Malar J. 2016;15:11.

12. Larsen DA, Martin A, Pollard D, Nielsen CF, Hamainza B, Burns M, et al. Leveraging risk maps of malaria vector abundance to guide control efforts reduces malaria incidence in Eastern Province, Zambia. Sci Rep. 2020;10:10307.

13. Keenan PB. Spatial decision support systems for vehicle routing. Decis Support Syst. 1998;22:65-71.

14. Nagy G, Salhi S. Heuristic algorithms for single and multiple depot vehicle routing problems with pickups and deliveries. Eur J Operational Res. 2005:162:126-41.

15. Derekenaris G, Garofalakis J, Makris C, Prentzas J, Sioutas S, Tsakalidis A. Integrating GIS, GPS and GSM technologies for the effective management of ambulances. Comput Environ Urban Syst. 2001;25:267-78.

16. Jones SG, Ashby AJ, Momin SR, Naidoo A. Spatial implications associated with using Euclidean distance measurements and geographic centroid imputation in health care research. Health Serv Res. 2010;45:316-27.

17. Brabyn L, Skelly C, Barnett R, Joseph A, Phillips D, Kohli K, et al. Modeling population access to New Zealand public hospitals. Int J Health Geogr. 2002;1:3.

18. Lee BY, Connor DL, Wateska AR, Norman BA, Rajgopal J, Cakouros BE, et al Landscaping the structures of GAVI country vaccine supply chains and testing the effects of radical redesign. Vaccine. 2015;33:4451-8. 
19. Brown ST, Schreiber B, Cakouros BE, Wateska AR, Dicko HM, Connor DL, et al. The benefits of redesigning Benin's vaccine supply chain. Vaccine. 2014;32:4097-103.

20. Metcalf CJE, Tatem A, Bjornstad ON, Lessler J, O'Reilly K, Takahashi S, et al. Transport networks and inequities in vaccination: remoteness shapes measles vaccine coverage and prospects for elimination across Africa. Epidemiol Infect. 2014;143:1457-66.

21. Linard C, Gilbert M, Snow RRW, Noor AMA, Tatem AJA, Carruthers R, et al. Population distribution, settlement patterns and accessibility across Africa in 2010. PLoS ONE. 2012;7:e31743.

22. Government of the Republic of Zambia, Ministry of Health. Zambia National Malaria Indicator Survey 2012. Lusaka, Zambia; 2012. 120 pp (https://www.malariasurveys.org/documents/Zambia_MIS_2012.pdf, accessed May $10^{\text {th }}, 2020$ ).

23. Kamanga A, Renn S, Pollard D, Bridges DJ, Chirwa B, Pinchoff J, et al. Open-source satellite enumeration to map households: planning and targeting indoor residual spraying for malaria. Malar J. 2015;14:345.

24. Google Product Forums. Google Map Maker graduates to Google Maps. 2016 Nov. Available: https://productforums.google.com/forum /\#!forum/map-maker.

25. Google Product Forums. Map Maker update [February 2017]. 2017. https ://productforums.google.com/forum/\#!topic/map-maker/5m7xLsiEFBO

26. OpenStreetMap. 2018. https://www.openstreetmap.org. Accessed 15 Dec 2018.

27. Dijkstra EW. A note on two problems in connexion with graphs. Numer Math. 1959;1:269-71.

28. Gething PW, Patil AP, Smith DL, Guerra CA, Elyazar IRF, Johnston GL, et al. A new world malaria map: Plasmodium falciparum endemicity in 2010. Malar J. 2011;10:378.
29. Wiebe A, Longbottom J, Gleave K, Shearer FM, Sinka ME, Massey NC, et al. Geographical distributions of African malaria vector sibling species and evidence for insecticide resistance. Malar J. 2017;16:85.

30. Pfeffer DA, Lucas TC, May D, Harris J, Rozier J, Twohig KA, et al. malariaAtlas: an R interface to global malariometric data hosted by the Malaria Atlas Project. Malar J. 2018;17:352.

31. Hijmans RJ. Introduction to the'raster'package (version 2.0-08). 2012.

32. Hijmans RJ, van Etten J. raster: Geographic analysis and modeling with raster data. 2012

33. R Core Development Team. R: A Language and Environment for Statistical Computing. HttpwwwR-Proj. 2010.

34. Cohen J. Weighted kappa: nominal scale agreement with provision for scaled disagreement or partial credit. Psychol Bull. 1968;70:213-20.

35. Omumbo JA, Noor AM, Fall IS, Snow RW. How well are malaria maps used to design and finance malaria control in Africa? PLOS ONE. 2013;8:e0053198.

36. Pinchoff J, Chaponda M, Shields T, Lupiya J, Kobayashi T, Mulenga M, et al. Predictive malaria risk and uncertainty mapping in Nchelenge District, Zambia: evidence of widespread, persistent risk and implications for targeted interventions. Am J Trop Med Hyg. 2015;93:1260-7.

37. Nikolov M, Bever CA, Upfill-Brown A, Hamainza B, Miller JM, Eckhoff PA, et al. Malaria elimination campaigns in the Lake Kariba Region of Zambia: a spatial dynamical model. PLoS Comput Biol. 2016;12:e1005192.

38. Dowell SF, Blazes D, Desmond-Hellmann S. Four steps to precision public health. Nat News. 2016:540:189.

\section{Publisher's Note}

Springer Nature remains neutral with regard to jurisdictional claims in published maps and institutional affiliations.
Ready to submit your research? Choose BMC and benefit from:

- fast, convenient online submission

- thorough peer review by experienced researchers in your field

- rapid publication on acceptance

- support for research data, including large and complex data types

- gold Open Access which fosters wider collaboration and increased citations

- maximum visibility for your research: over $100 \mathrm{M}$ website views per year

At BMC, research is always in progress.

Learn more biomedcentral.com/submissions 